\title{
AN EYE SANATORIUM : SURVEY OF ONE YEAR'S WORK
}

BY

\author{
D. P. CHOYCE AND A. G. CROSS
}

London

\section{OCULAR TUBERCULOSIS}

Tuberculosis of the eye appears in many different forms, in all grades of severity, and at all ages. The pathological changes in the ocular structures may be due to the presence of the Mycobacterium tuberculosis or to the effects of hypersensitivity of some part of the eye to tuberculoprotein, as the result of a previous tuberculous infection in the body, often in the lymphatic glands, or lungs. In some cases the clinical manifestations are the result of a combination of both these factors.

DiaGNOSIS.-This is rendered difficult by the fact that no serological test exists which will demonstrate the presence of an active tuberculous lesion in the body, though much investigation has been carried out to discover such a reaction both in the serum and in the aqueous humour. The Mantoux reaction is a measure of skin sensitivity to tuberculoprotein, and in some cases this may be considered to be parallel to the ocular sensitivity. The ocular sensitivity may however be higher than that of the skin, and as in this country most adults give a positive skin reaction, the diagnostic value of the Mantoux reaction is not great. According to Woods (1951), the diagnosis of intra-ocular tuberculosis depends upon:

(1) The presence of signs and symptoms compatible with ocular tuberculosis.

(2) Exclusion of other aetiological factors.

(3) The presence of a focus of tuberculosis, active or healed, somewhere in the body.

(4) Tuberculin skin reactions.

Many cases, even after the consideration of these factors, remain indefinite, and the diagnosis depends ultimately upon the experience and opinion of the examining ophthalmologist. Tuberculosis of the eye-lids and ocular adnexa is easier, because portions of tissue can be examined for the presence of organisms and for diagnostic histological appearances.

TREATMENT.-Over many years, this has presented an insoluble problem.

* Received for publication April 7, 1953. 
Some forms of the disease have tended to settle down fairly readily, while others have taken a course of steady deterioration which has led to loss of the eye. Others have proceeded in chronic fashion for months or years, and have, ultimately, resulted in great visual disability. The treatment of the general condition of the patient, with the object of raising his general immunity, has always been an important consideration in therapy, but facilities for sanatorium treatment for ocular cases in Great Britain have not existed, though some patients have been able to go to Switzerland to such centres as the Guardaval Clinic at Davos (Choyce, 1952). Local treatment with mydriatics has been undertaken, together with such surgical procedures as have been indicated. The introduction of the chemotherapeutic drugs, streptomycin, promizol, and para-amino-salicylic acid was an advance which has resulted in the more rapid cure of certain tuberculous ocular lesions. The position of tuberculin in treatment has been indefinite. The object of injecting this substance, initially, was to produce an immune reaction, but this it failed to do. Now that the concept of tissue hypersensitivity has been appreciated, it is suggested that, commencing with small doses and proceeding by small increases, tuberculin may be used to desensitize patients who are sensitive to tuberculoprotein. This requires regular, gradually increasing injections over a prolonged period.

\section{Conception and Plan of Eyf Sanatorium}

The idea of opening a sanatorium devoted to the treatment of ocular tuberculosis in Great Britain has in the past been suggested repeatedly by different ophthalmic authorities. In those times patients with ocular tuberculosis could be sent to convalescent homes, but only for relatively short periods, and while in these institutions they were not under ophthalmic care nor receiving treatment from a skilled nursing staff. A centre was conceived, therefore, at which patients could stay for any required period, and, in general, for a minimum of 4 months. It was planned that they should be under regular ophthalmic supervision, and under the care of experienced ophthalmic nurses. The South-Eastern Metropolitan Regional Hospital Board made 28 beds available at the Whiteoak Hospital, Swanley, Kent, and responsibility for their medical and nursing care was given to.the Moorfields, Westminster and Central Eye Hospital. The unit was fully equipped to carry out all routine ophthalmic procedures, and, since it was in close proximity to the Kettlewell Sanatorium, all necessary diagnostic procedures for pulmonary tuberculosis were readily available, and Dr. P. Forgacs the Medical Superintendent, was able to make routine examinations of all patients. Arrangements were made for occupational therapy, and for schooling for the children, and the Almoner's department of the Moorfields branch of the hospital undertook the social aspect of the patients' care.

The Swanley Eye Sanatorium was opened by the Minister of Health, Mr. 
Hilary Marquand, on June 28, 1951, for the care of cases of ocular tuberculosis from all parts of the United Kingdom, and during the first year 47 patients were treated and discharged.

\section{Routine Procedures of Diagnosis}

(1) A full history with special reference to possible tuberculous lesions either in the patient or in near relations.

(2) A full examination of the eyes and a full general examination of the rest of the body.

(3) Radiological examination of the chest for possible lesions either in the lungs or in the mediastinal lymphatic glands.

(4) Mantoux reaction: the first intra-cutaneous injection was $0.1 \mathrm{ml} .1 / 10,000$ old tuberculin. A negative reaction indicated a test with $1 / 1,000$ old tuberculin and if this was negative one with $1 / 100$ old tuberculin. A negative reaction with 1/100 old tuberculin was followed by an injection of B.C.G. vaccine and a repeat of the Mantoux reaction with $1 / 100$ tuberculin in 6 weeks.

(5) Erythrocyte sedimentation rate estimated monthly, weight weekly, and sputum as indicated by examination of the chest.

Patients spent the first 2 weeks after admission resting in bed, except for toilet purposes. Thereafter they got up for increasing periods until they were out of bed throughout the day, except for a rest of one hour after meals. Streptomycin and para-amino-salicylic acid were given where there was evidence to suggest the presence of Mycobacterium tuberculosis, tuberculin where the skin sensitivity was high and the ocular lesion had an appearance suggesting that it was due to hypersensitivity, and cortisone by subconjunctival injection or as drops in acute inflammatory lesions of the eye which appeared to be threatening corneal or lens transparency.

The average length of stay has been 4 months; the shortest being 2 months and the longest over one year. It has been suggested that 4 months is the minimum period in which ocular tuberculous lesions can be expected to settle. About one quarter of the patients admitted were diagnosed as suffering from Boeck's sarcoid, which many authorities regard as a modified form of tuberculosis. It appears that, while some cases of sarcoidosis settle rapidly under a sanatorium regime, the improvement is not so constant as in cases of tuberculosis.

The majority of patients and particularly the children put on weight during their stay; in the two cases in which weight was lost it was thought that this was due to worry over possible impending blindness. The average increase in weight was $7 \mathrm{lb}$., but one small girl with conjunctival tuberculosis put on $38 \mathrm{lb}$. in 5 months.

\section{Analysis of CASES AND Results}

During the first year of work at the Eye Sanatorium 47 cases were admitted and discharged (Table I, pp. 408-411). 


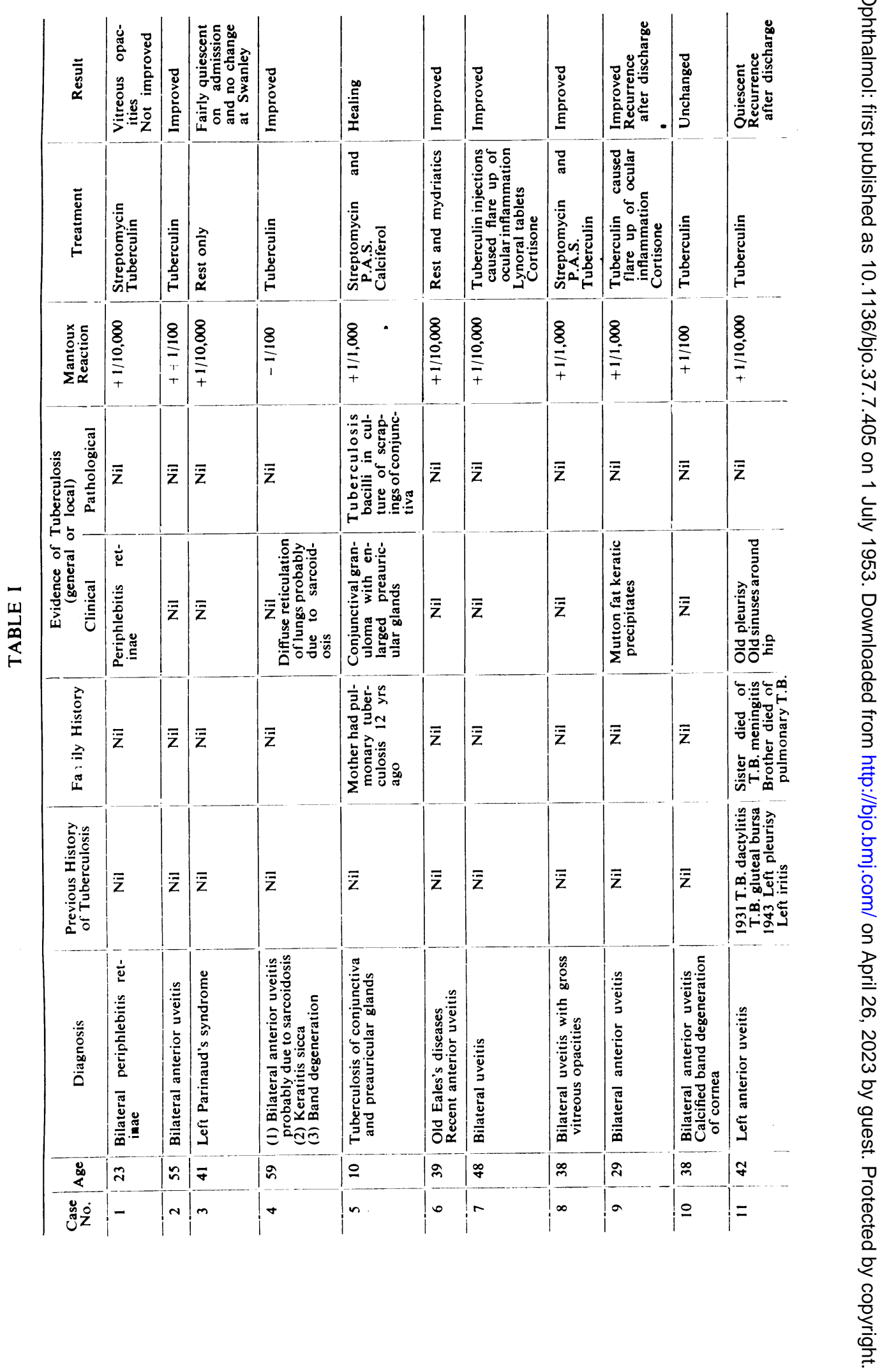




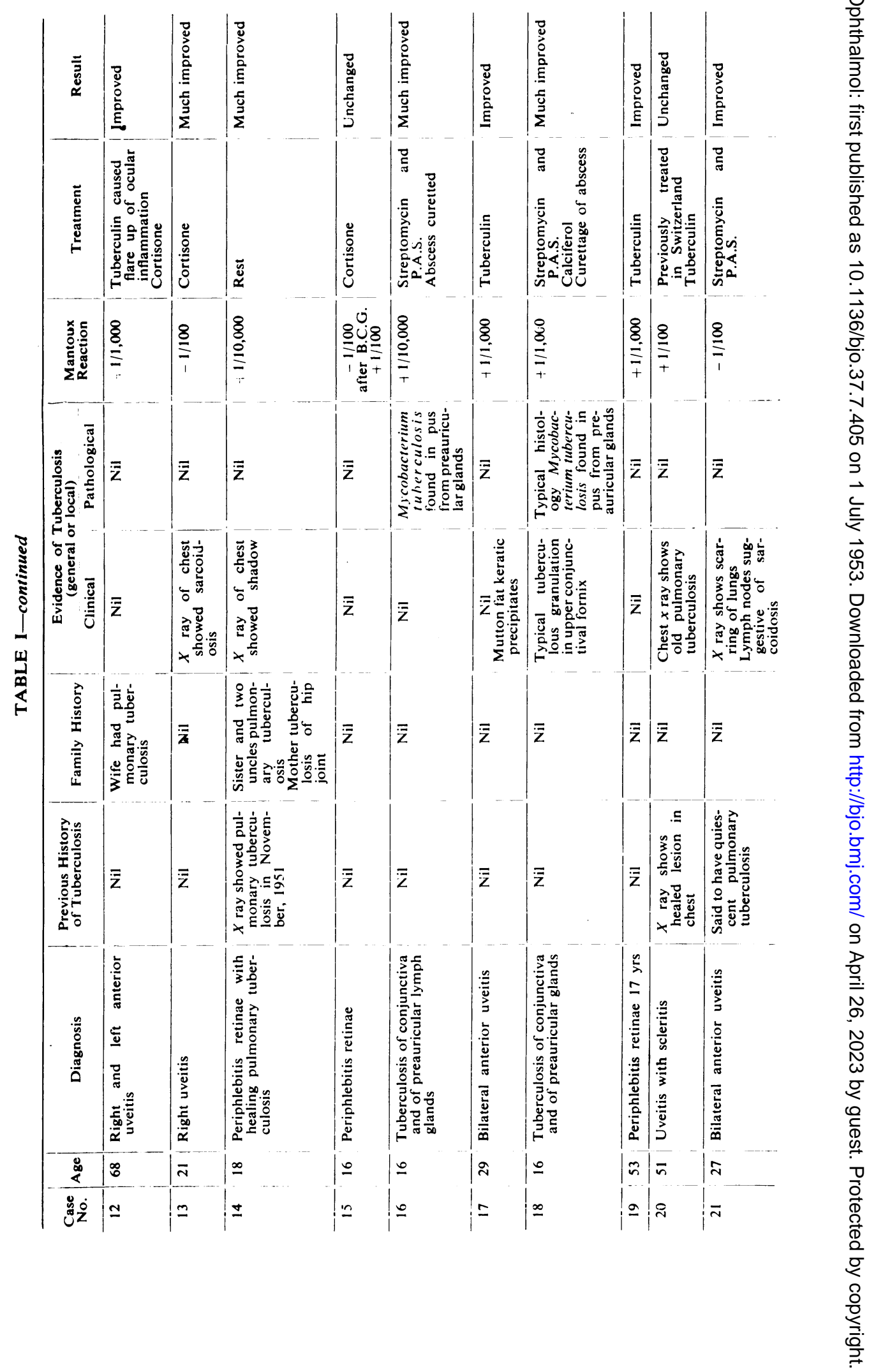


AN EYE SANATORIUM

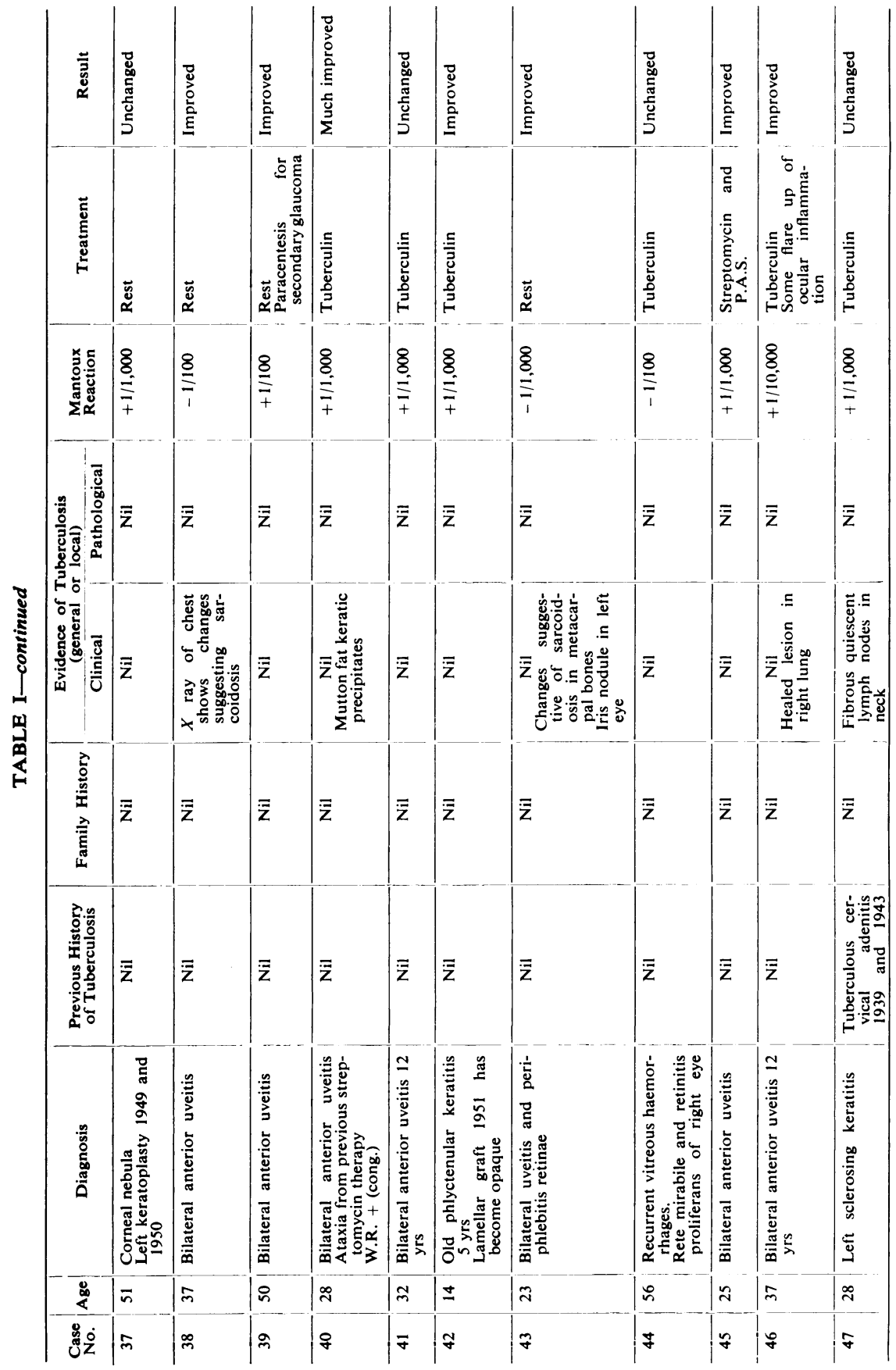


The diagnosis of these 47 cases is shown in Table II. About half the cases admitted during the first year were the result of tuberculous infection, or possibly due to such infection. Nearly half the remainder (one-quarter of the whole) were possible cases of sarcoidosis. The results of treatment at the sanatorium are shown in Table III.

TABLE II

DIAGNOSIS

\begin{tabular}{|c|c|c|c|c|c|c|}
\hline Ocular Condition & $\begin{array}{l}\text { Tuber- } \\
\text { culosis }\end{array}$ & $\begin{array}{l}\text { Doubtful } \\
\text { Tuber- } \\
\text { culosis }\end{array}$ & $\begin{array}{c}\text { Sarcoi- } \\
\text { dosis }\end{array}$ & $\begin{array}{c}\text { Doubtful } \\
\text { Sarcoi- } \\
\text { dosis }\end{array}$ & $\begin{array}{l}\text { Non-specific } \\
\text { Inflam- } \\
\text { mation }\end{array}$ & Total \\
\hline $\begin{array}{ll}\text { Uveitis ... } & \ldots \\
\text { Anterior uveitis } & \ldots \\
\text { Posterior uveitis } & \ldots \\
\text { Periphlebitis retinae } & \ldots \\
\text { Conjunctivitis ... } & \ldots \\
\text { Keratitis } & \ldots \\
\text { Parinaud's syndrome } & \ldots\end{array}$ & $\begin{array}{l}- \\
\overline{-} \\
3 \\
3 \\
2 \\
-\end{array}$ & $\begin{array}{l}2 \\
9 \\
\frac{1}{1} \\
1 \\
1\end{array}$ & $\begin{array}{l}1 \\
- \\
- \\
-\end{array}$ & $\begin{array}{l}\overline{6} \\
1 \\
2 \\
- \\
-\end{array}$ & $\begin{array}{l}2 \\
\frac{7}{2} \\
\frac{3}{-}\end{array}$ & $\begin{array}{r}5 \\
23 \\
1 \\
8 \\
3 \\
6 \\
1\end{array}$ \\
\hline Totals ... & 8 & 14 & 2 & 9 & 14 & 47 \\
\hline
\end{tabular}

TABLE III

RESULTS OF TREATMENT

\begin{tabular}{|c|c|c|c|c|c|c|}
\hline Diagnosis & & $\begin{array}{l}\text { Much } \\
\text { Improved }\end{array}$ & Improved & Unchanged & Worse & Total \\
\hline 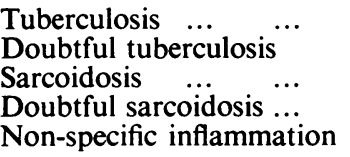 & $\begin{array}{l}\cdots \\
\cdots \\
\cdots \\
\cdots \\
\cdots\end{array}$ & $\begin{array}{l}5 \\
1 \\
1 \\
1 \\
-\end{array}$ & $\begin{array}{r}2 \\
9 \\
1 \\
4 \\
10\end{array}$ & $\begin{array}{l}1 \\
4 \\
3 \\
4\end{array}$ & $\frac{\bar{Z}}{\overline{1}}$ & $\begin{array}{r}8 \\
14 \\
2 \\
9 \\
14\end{array}$ \\
\hline Totals $\ldots . \quad \ldots$ & $\ldots$ & 8 & 26 & 12 & 1 & 47 \\
\hline
\end{tabular}

These figures, which are so small as to be statistically valueless, suggest that cases of tuberculosis respond well to treatment at the sanatorium, while cases of possible tuberculosis, sarcoidosis and possible sarcoidosis, and nonspecific cases, appear, generally, to improve at the sanatorium, but not in such a marked manner as the definite tuberculosis cases.

It is too early to evaluate desensitization therapy by tuberculin, because the period of treatment may last for 2 years or more and must be followed by a period of observation.

It has appeared that cases of sarcoidosis associated with acute uveitis have responded satisfactorily to local applications of cortisone.

\section{Discussion}

It is apparent that cases of ocular tuberculosis respond satisfactorily to routine treatment in a sanatorium. The urgent problem which requires 
solution is a rapid method of establishing a definite diagnosis. The methods described, which have been used during the past year, are insufficient. In cooperation with the Pathological Department of the Institute of Ophthalmology, the Middlebrook-Dubos test is to be carried out on all patients. This is a haemagglutination test in which red blood corpuscles treated with an extract of the Mycobacterium tuberculosis are mixed with the sera of patients who are suspected of having an active tuberculous lesion. Agglutination of the red blood corpuscles at a titre of $1: 8$ is regarded as positive for active tuberculosis, though it is agreed by all observers that some cases of active disease do not give a positive result. This test has been used in Great Britain in pulmonary cases, and has been regarded as valueless, but it has not, so far as is known, been employed previously in Great Britain in ophthalmic cases, though it has been widely performed in Switzerland (Brodhage, 1952) where great reliance is placed upon it.

It is proposed, in addition, to undertake this test upon the aqueous humour, removed by puncture from the anterior chamber of all patients, and to investigate it for its cell content and for the presence of micro organisms. Further experience may lead to more accurate assessment of clinical signs and symptoms for the purposes of diagnosing tuberculosis of the eye.

The treatment of ocular tuberculosis, once the diagnosis is established, is not an insurmountable problem. Streptomycin and para-amino-salicylic acid give satisfactory results where the Mycobacterium tuberculosis is present, and iso-nicotinamide hydrazine is a drug which is also being used in these patients. The sanatorium regime is useful, and tuberculin may be of value in selected cases.

Problems which are not met in hospital must be faced and solved in a sanatorium when the patients remain for long periods. Personalities tend to clash when patients are in close contact for many weeks, and an ideal institution would have single rooms, double rooms, and rooms with four beds, so that the introvert as well as the more gregarious patient could be happily settled. Occupational therapy and entertainment are essential, because the time may pass slowly for patients who cannot read or are not allowed to do so. The help of the almoner is important, because, especially in the case of men, economic problems arise which must be solved to allow that peace of mind which is essential if the patient is to benefit.

One-quarter of the patients admitted to Swanley during the first year have shown no definite evidence of tuberculous infection, but in most of them the state of their eyes improved during their stay. It would, possibly, be unjustifiable to maintain an Eye Sanatorium for the benefit of such patients only, but the fact that they are improved by this, and often by no other treatment, is added emphasis on the value of such an institution. The Eye Sanatorium also collects together many cases of peculiar interest which may be of value for research and teaching purposes. 


\section{CONCLUSIONS}

(1) Treatment at the Eye Sanatorium is of real value in all cases of ocular tuberculosis, and of some value in non-specific cases of uveitis and of periphlebitis retinae.

(2) Confirmatory tests for the presence of tuberculous infection of the eye, whether bacterial or due to hypersensitivity, are an urgent requirement.

(3) Occupational therapy for the patients in the Eye Sanatorium is a necessary part of the therapeutic regime.

(4) An ideal Eye Sanatorium would have ward units of one, two, and four beds, so that patients who wish to do so can have some amount of relative or absolute privacy. Day rooms are also necessary.

(5) In order to carry out its functions adequately, patients should be admitted to the Eye Sanatorium immediately upon the request of the surgeon in charge of the case, and more beds than those at present available are, therefore, likely to be required.

\section{REFERENCES}

Brodhage, H. von (1952). Beitr. Klin. Tuberk., 107, 494.

CHOYCE, D. P. (1952). Trans. ophthal. Soc. U.K., 72, 279.

Woods, A. C. (1951). In "Systemic Ophthalmology", ed. A. Sorsby. Butterworth, London. 